\title{
Supporting choices about HIV disclosure in the workplace: A cross-Canada survey of strategies
}

\author{
Gayle Restall ${ }^{\mathrm{a}, *}$, Alexandria Simms ${ }^{\mathrm{a}}$, Emily Etcheverry ${ }^{\mathrm{a}}$, Kerstin Roger ${ }^{\mathrm{b}}$, Dawn James ${ }^{\mathrm{c}}$, \\ Pumulo Roddy ${ }^{\mathrm{d}}$, Wendy Porch ${ }^{\mathrm{e}, 1}$, Jeff Potts ${ }^{\mathrm{f}}$, Dave Skitch ${ }^{\mathrm{g}}$ and Tammy Yates ${ }^{\mathrm{e}}$ \\ ${ }^{a}$ Department of Occupational Therapy, College of Rehabilitation Sciences, Rady Faculty of Health Sciences, \\ University of Manitoba, Winnipeg, MB, Canada \\ ${ }^{\mathrm{b}}$ Department of Community Health Sciences, Rady Faculty of Health Sciences, University of Manitoba, \\ Winnipeg, MB, Canada \\ ${ }^{\mathrm{c}}$ Nine Circles Community Health Centre, Winnipeg, MB, Canada (at the time of the study) \\ ${ }^{\mathrm{d}}$ Sexuality Education Resource Centre, Winnipeg, MB, Canada \\ e Realize, Toronto, ON, Canada \\ ${ }^{\mathrm{f}}$ Canadian Positive People Network, Ottawa, ON, Canada (at the time of the study) \\ ${ }^{\mathrm{g}}$ Toronto HIV/AIDS Network, Toronto, ON, Canada (at the time of the study)
}

Received 12 June 2018

Accepted 20 January 2019

\begin{abstract}
. whether or not to disclose their HIV status in the workplace.

Keywords: Employment, service delivery, decision-making

*Address for correspondence: Gayle Restall, Department of Occupational Therapy, College of Rehabilitation Sciences, Rady Faculty of Health Sciences, University of Manitoba, R106-771, McDermot Avenue, Winnipeg, MB, Canada, R3E 0T6. Tel.: +1 204975 7736; E-mail: gayle.restall@umanitoba.ca.

${ }^{1}$ Currently at Centre for Independent Living in Toronto, Toronto, ON, Canada.
\end{abstract}

BACKGROUND: People living with human immunodeficiency virus (HIV) often make highly personal decisions about

OBJECTIVE: We aimed to determine current practices that support people living with HIV to make workplace disclosure decisions and to understand factors that affect disclosure decision-making.

METHODS: Ninety-four people who provide health, social and peer-based services responded to an on-line survey about their experiences supporting workplace disclosure decisions of employees living with HIV.

RESULTS: Respondents identified a range of strategies to support workplace disclosure decision-making. One-third of respondents were only a little or not confident in their abilities to support people in making disclosure decisions and $32 \%$ expressed little or no confidence in the resources available. Respondents working at HIV-specific organizations, as compared to respondents not working at those organizations, were more confident supporting people with disclosure decisions and in available resources, $p<.05$. Perceived barriers to disclosure decisions included stigma, lack of knowledge, and personal factors. Supports for decision-making resided within personal, workplace and societal contexts.

CONCLUSIONS: The study provides important understanding about the complexity of disclosure decision-making and strategies that people living with HIV can use to address this complex issue.

\section{Introduction}

Human immunodeficiency virus (HIV) is now considered a chronic health condition [1]. People living with HIV can live long-term in good health interspersed with periods of disability [2]. Immediate and long-term physical, and neurocognitive 
consequences of HIV and its treatments, along with the cumulative effects of aging, can increase episodes of poor health and disability [3], and can create challenges for people living with HIV to obtain and sustain competitive employment.

Workforce participation facilitates economic independence, and is positively associated with retention in HIV care [4, 5], physical and mental health [6], higher quality of life [7] and adherence to antiretroviral treatment [8]. Interventions that support employment and sustain workforce participation are priority areas for HIV research $[9,10]$. A strong body of evidence literature suggests the need for interventions that assist people living with HIV to make informed decisions related to disclosure or nondisclosure in the workplace [11-15]. However, little is known about what supports are currently available to assist individuals in making workplace disclosure decisions. This study explored current practices in this area.

HIV continues to be a highly stigmatized health condition [16] making disclosure of HIV status in the workplace a high-stakes decision. Decisions to disclose, or not, are highly personal and contextual $[17,18]$. Although some people living with HIV have disclosed their HIV status in all social contexts, disclosure decisions, for most, are fluid over time and consist of multiple disclosure events [19]. Reasons to disclose can include the need for workplace accommodations, such as shortened or flexible work schedules, change in work locations, time off for appointments, and adaptations to work tasks and equipment [5, 20-22]. However, in most cases in Canada, disclosure of a specific diagnosis is not necessary to obtain accommodations. People living with HIV may also want to explain to supervisors and coworkers why they have health-related absences and need time off work for medical appointments [23]. Other people living with HIV may be considering workplace disclosure because they want to reduce the stress they feel in keeping a secret from their colleagues [24]. Still others may be motivated to disclose to reduce HIV-related stigma and promote social justice for people living with HIV $[14,15]$.

Although reasons for non-disclosure or selective disclosure are also diverse [19], HIV-related stigma remains one of the most salient reasons for nondisclosure [12]. Fear of discrimination, job loss and social marginalization can be deterrents to disclosure. Reluctance to disclose HIV status in the workplace may be compounded for people experiencing intersecting forms of stigmatization (e.g., men who have sex with men, racialized people, newcomers to a country), and those who may be economically vulnerable (e.g., women, low-income earners) [13]. Selective disclosure to a particular supervisor or co-worker can also raise concerns about thirdparty disclosure that may result in stigmatization [24]. In addition, some people living with HIV may be reluctant to disclose having previously observed or experienced negative reactions to disclosure [15]. Others may not disclose because they don't believe it is relevant to their employment [15] and is not required even when in cases in which accommodations are requested.

Greater understanding about the complexity of workplace disclosure and ways to support people living with HIV with decision-making can increase opportunities for implementing important coping strategies [25]. People living with HIV are increasingly able to obtain and maintain long-term competitive employment, but little is known about the supports that are available to assist them with difficult and complex disclosure decisions specific to workplace environments. The purpose of this study was to determine current practices related to supporting people living with HIV to make workplace disclosure decisions and to understand the barriers and supports to disclosure decision-making.

\section{Methods}

\subsection{Study design}

We conducted a cross-sectional Canada-wide email survey. A university-based Research Ethics Board approved the study.

\subsection{Survey development}

A team of researchers, health and social service providers, advocacy organization representatives and people living with HIV developed the survey based on a review of academic and grey literature and their expertise. The intent was to gather descriptive information on current supports for people living with HIV making workplace disclosure decisions with the understanding that disclosure decisions are complex and the best options for disclosure or non-disclosure are personal and context-dependent.

The survey was structured to collect demographic information, respondents' experiences supporting people living with HIV (4-point scale), and their 
confidence supporting people living with HIV to make workplace disclosure decisions (4-point scale). Two survey questions presented 5-item lists of direct and indirect strategies used to support people living with HIV in making workplace disclosure decisions. Direct strategies were those respondent used to directly support decision-making. Indirect strategies involved referring the person living with HIV to another person or resource. Respondents were asked to indicate which strategies they used and their perception of each strategy's effectiveness (4point scale). Finally, through open-ended questions, respondents were asked to list three values that people hold that affect workplace disclosure decisions, three barriers, and three supports for making workplace disclosure decisions. We also provided an opportunity for respondents to add additional information.

\subsection{Sampling frame}

We recruited people providing supports and services (health, social services and peer-based) to people living with HIV to make workplace disclosure decisions, acknowledging the range of available supports and organizations that may provide that support. We identified potential participants by scanning public listings of HIV-related organizations, through the research team's networks of agencies and through the contact lists of Realize. Realize is a national organization with a mandate to improve the lives of people living with HIV and other episodic disabilities through rehabilitation care, support and service. We asked recipients of the e-mail survey invitation to forward the invitation to others who they thought might be interested.

We sent invitations to participate in the study to 212 e-mail addresses obtained through contact lists as noted above. Using methodology recommended by Dillman, Smyth and Christian [26], we sent an initial e-mail invitation to participate in the study with a link to the online survey; a first e-mail reminder one week later; and a final e-mail reminder one to two weeks prior to the survey closure. Sixteen of the initial e-mails were returned; seven were undeliverable to an incomplete or unknown e-mail address, and nine generated an automatic reply indicating the recipient was no longer working in that position or was away on extended leave.

The survey was administered between May 1st and June 11th 2017 using Research Electronic Data Capture (REDCap), a secure web-based data capture [27]. A consent disclosure statement preceding the ques- tionnaire indicated that submitting the response to the survey was confirmation of consent to participate. Prior to the release of the survey, we did Beta tests with members of the research team that included people with a variety of backgrounds and perspectives to ensure the software was running smoothly and questions were clear and comprehensible.

\subsection{Analysis}

Responses to demographic and Likert scaled questions were analyzed descriptively. We used the Mann-Whitney $U$ test to determine whether there were differences between respondents who work in HIV-specific organizations and those who do not, in their experience and level of confidence in providing support to people living with HIV, and confidence in the resources available to support workplace disclosure decisions. We also examined whether there were differences between respondents who reported that they live with HIV and those who did not, on the same variables. The level of significance was set at $p<.05$ (two-tailed).

We analyzed the open-ended responses to questions about values, barriers and supports that affect decision-making regarding workplace disclosure using a general inductive approach (28). One member of the research team coded all responses and then reviewed coding to identify categories and themes. The team member reviewed responses to the request for additional information at the end of the survey in relation to the themes that emerged from the items listed as values, barriers and supports. Comments from respondents living with HIV and those who are not, were coded separately. To promote trustworthiness, four members of the research team met to review and discuss the categories and themes, and adjusted the naming and categorizing of themes through consensus.

\section{Results}

\subsection{Sample}

A total of 132 responses were recorded by the Web survey; 21 records were removed as no responses to survey questions were recorded. We removed an additional 17 records that did not contain any data related to key survey questions about the use and effectiveness of strategies to support people living with HIV to make decisions about whether or not to disclose 
Table 1

Survey respondents' level of experience and confidence supporting disclosure decision-making, $N=94$

\begin{tabular}{|c|c|c|c|c|c|}
\hline \multirow[t]{2}{*}{ Survey Question - Experience } & \multicolumn{5}{|c|}{ Response $n(\%)$} \\
\hline & $\begin{array}{c}\text { No } \\
\text { experience }\end{array}$ & $\begin{array}{c}\text { A little } \\
\text { experience }\end{array}$ & $\begin{array}{l}\text { Moderate } \\
\text { experience }\end{array}$ & $\begin{array}{l}\text { Extensive } \\
\text { experience }\end{array}$ & Missing \\
\hline $\begin{array}{l}\text { What is your overall level of experience with providing care, } \\
\text { treatment and/or support for people living with HIV? }\end{array}$ & $1(1.06)$ & $17(18.09)$ & $34(36.17)$ & $42(44.68)$ & $0(0.00)$ \\
\hline $\begin{array}{l}\text { What is your overall level of experience supporting people } \\
\text { living with HIV to make decisions about disclosure of } \\
\text { their health status to other people? }\end{array}$ & $3(3.19)$ & $33(35.11)$ & $29(30.85)$ & $29(30.85)$ & $0(0.00)$ \\
\hline $\begin{array}{l}\text { What is your overall level of experience supporting people } \\
\text { living with HIV to make decisions about disclosure of } \\
\text { their health status specifically in the workplace? }\end{array}$ & $17(18.09)$ & $30(31.91)$ & $29(30.85)$ & $18(19.15)$ & $0(0.00)$ \\
\hline Survey Question - Confidence & $\begin{array}{l}\text { Not } \\
\text { confident }\end{array}$ & $\begin{array}{l}\text { A little } \\
\text { confident }\end{array}$ & $\begin{array}{c}\text { Moderately } \\
\text { confident }\end{array}$ & $\begin{array}{l}\text { Very } \\
\text { confident }\end{array}$ & Missing \\
\hline $\begin{array}{l}\text { Overall, how confident are you in your ability to support } \\
\text { people in making disclosure decisions? }\end{array}$ & $4(4.26)$ & $27(28.72)$ & $35(37.23)$ & $27(28.72)$ & $1(1.06)$ \\
\hline $\begin{array}{l}\text { Overall, how confident are you in the resources that are } \\
\text { available to you for supporting people in making } \\
\text { disclosure decisions? }\end{array}$ & $11(11.70)$ & $19(20.21)$ & $51(54.26)$ & $13(13.83)$ & $0(0.00)$ \\
\hline
\end{tabular}

their HIV status in the workplace. The final sample was 94 ; the majority $(n=54,57.45 \%)$ were women, and had some post-secondary education $(n=85$, $90.42 \%$ ). Ethnic/cultural origins were reported as White $(n=59,62.77 \%)$, Asian $(n=9,9.57 \%)$, Black $(n=6,6.38 \%)$, and Indigenous $(n=6,6.38 \%)$; the remainder reported multiple, mixed or another ethnic/cultural origin. The majority $(n=73,77.66 \%)$ of respondents reported they work for an HIV/AIDS service organization (ASO) or a community health organization that provides HIV-specific services. The majority of respondents $(51.06 \%)$ reported that they were currently working as a health and/or social service provider. Just over a quarter of respondents $(n=24,25.53 \%)$ reported that they were living with HIV, $75.00 \%$ of whom reported living with HIV more than 15 years.

\subsection{Experiences and confidence}

Table 1 provides response rates for each survey question about experience and confidence levels supporting disclosure decision-making. Almost all respondents $(n=93,98.94 \%)$ reported a little to extensive experience supporting people living with HIV. Fewer $(n=91,96.81 \%)$ respondents reported any level of experience supporting people living with HIV to make disclosure decisions in general, whereas even fewer $(n=77 ; 81.91 \%)$ reported some level of experience supporting people to make decisions related specifically to workplace disclosure of HIV status. A third $(n=31,32.98 \%)$ of respondents were only a little or not confident in their ability to support people in making disclosure decisions. Similarly, 30 respondents $(31.91 \%)$ expressed a little or no confidence in the resources available to help them support people making disclosure decisions.

We explored whether there were differences in respondents' experience and confidence related to whether or not they worked for an HIV-specific organization (ASO or an HIV-specific heath centre). Both groups reported the same level of experience, $p>.05$. However, we found that respondents working at HIV-specific organizations $(n=72)$ compared to respondents not working at those organizations $(n=21)$ were more confident supporting people with workplace disclosure decisions $U=488, p<.01$. Likewise, respondents working at HIV-specific organizations $(n=73)$ compared to respondents not working at those organizations $(n=21)$ were more confident in the resources available to support workplace disclosure, $U=365.00, p<.01$. We also explored whether respondents living with HIV had different levels of experience and confidence related to supporting others with workplace disclosure decisions. We found that respondents living with HIV $(n=24)$ compared to those not living with HIV $(n=69)$ reported they had more experience supporting workplace disclosure decision-making $U=611.00, p<.05$. In addition, respondents living with HIV $(n=24)$ were more confident supporting people with workplace disclosure decisions than respondents not living with HIV $(n=68) U=575.00$, $p<.05$. Respondents living with HIV $(n=24)$ were also more confident than other respondents $(n=69)$ with the resources available $U=604.50 ; p<.05$. 
Table 2

Effectiveness ratings of pre-determined strategies to support people living with HIV to make workplace disclosure decisions, $\mathrm{N}=94$

\begin{tabular}{|c|c|c|c|c|c|c|}
\hline \multirow[t]{2}{*}{ Strategy } & \multicolumn{6}{|c|}{ Response $n(\%)$} \\
\hline & $\begin{array}{l}\text { Not very } \\
\text { effective }\end{array}$ & $\begin{array}{l}\text { A little } \\
\text { effective }\end{array}$ & $\begin{array}{l}\text { Moderately } \\
\text { effective }\end{array}$ & $\begin{array}{c}\text { Very } \\
\text { effective }\end{array}$ & $\begin{array}{l}\text { Don't } \\
\text { know or } \\
\text { don't use }\end{array}$ & Missing \\
\hline \multicolumn{7}{|l|}{ Direct strategies } \\
\hline $\begin{array}{l}\text { Brief counseling (one session, as part of another } \\
\text { intervention, e.g., clinical follow-up) }\end{array}$ & $7(7.45)$ & $14(14.89)$ & $30(31.91)$ & $23(24.47)$ & $20(21.28)$ & $0(0.00)$ \\
\hline $\begin{array}{l}\text { Intensive disclosure counseling (one or more sessions that } \\
\text { are specifically targeted at addressing the issue of } \\
\text { disclosure in general) }\end{array}$ & $0(0.00)$ & $0(0.00)$ & $17(18.09)$ & $35(37.23)$ & $41(43.62)$ & $1(1.06)$ \\
\hline $\begin{array}{l}\text { Intensive workplace disclosure counseling (one or more } \\
\text { sessions that are specifically targeted at addressing the } \\
\text { issue of workplace disclosure) }\end{array}$ & $1(1.06)$ & $1(1.06)$ & $14(14.89)$ & $30(31.91)$ & $46(48.94)$ & $2(2.13)$ \\
\hline Referral to web or print resources & $6(6.38)$ & $24(25.53)$ & $38(40.43)$ & $9(9.57)$ & $16(17.02)$ & $1(1.06)$ \\
\hline Use of a structured decision aid for disclosure & $2(2.13)$ & $9(9.57)$ & $19(20.21)$ & $13(13.83)$ & $47(50.00)$ & $4(4.26)$ \\
\hline Other direct strategy & $0(0.00)$ & $0(0.00)$ & $3(3.19)$ & $7(7.45)$ & $53(56.38)$ & $31(32.98)$ \\
\hline \multicolumn{7}{|l|}{ Indirect strategies } \\
\hline Development of web-based resources & $4(4.26)$ & $16(17.02)$ & $33(35.11)$ & $7(7.45)$ & $31(32.98)$ & $3(3.19)$ \\
\hline Development of print resources & $1(1.06)$ & $22(23.40)$ & $31(32.98)$ & $10(10.64)$ & $27(28.72)$ & $3(3.19)$ \\
\hline Internal referral to someone in same agency & $0(0.00)$ & $0(0.00)$ & $18(19.15)$ & $32(34.04)$ & $38(40.43)$ & $6(6.38)$ \\
\hline Referral to another agency & $2(2.13)$ & $2(2.13)$ & $22(23.40)$ & $18(19.15)$ & $39(41.49)$ & $11(11.70)$ \\
\hline Advocacy & $1(1.06)$ & $8(8.51)$ & $21(22.34)$ & $33(35.11)$ & $27(28.72)$ & $4(4.26)$ \\
\hline Other indirect strategy & $0(0.00)$ & $1(1.06)$ & $2(2.13)$ & $3(3.19)$ & $49(52.13)$ & $39(41.49)$ \\
\hline
\end{tabular}

Table 3

Summary of respondents' ratings of use and relative effectiveness of pre-determined strategies to support people living with HIV in making workplace disclosure decisions from most frequently used to least frequently used

\begin{tabular}{lcc}
\hline Strategy & $\begin{array}{c}\text { Used by } n(\%) \text { of } \\
\text { respondents, } \\
N=94\end{array}$ & $\begin{array}{c}\text { Rated as moderately } \\
\text { or very effective by } \\
\text { respondents who use } \\
\text { the strategy, } n(\%)\end{array}$ \\
\hline $\begin{array}{l}\text { Direct support strategies } \\
\text { Referral to web or print resources }\end{array}$ & $77(81.91)$ & $47(61.04)$ \\
$\quad$ Brief counseling (one session, as part of another & $74(78.71)$ & $53(71.62)$ \\
intervention, e.g., clinical follow-up) & $52(55.32)$ & $52(100.00)$ \\
$\quad \begin{array}{l}\text { Intensive disclosure counseling (one or more sessions } \\
\text { that are specifically targeted at addressing the issue of } \\
\text { disclosure in general) }\end{array}$ & & \\
Intensive workplace disclosure counseling (one or more & $46(48.94)$ & $44(95.65)$ \\
sessions that are specifically targeted at addressing the & & \\
issue of workplace disclosure) & & \\
Use of a structured decision aid for disclosure & $43(45.74)$ & $41(64.06)$ \\
\hline Indirect support strategies & & $54(85.71)$ \\
Development of print resources & $64(68.09)$ & $40(66.67)$ \\
Advocacy & $63(67.02)$ & $50(100.00)$ \\
Development of web-based resources & $60(63.83)$ & $40(90.91)$ \\
Internal referral to someone in same agency & $50(53.19)$ & \\
Referral to other agency & $44(46.81)$ & \\
\hline
\end{tabular}

\subsection{Strategies}

To determine the strategies used to support people living with HIV to make workplace disclosure decisions, we asked respondents to rate their perceptions of the relative effectiveness of two pre-identified lists of direct and indirect strategies. Table 2 provides details of respondents' ratings of effectiveness of each pre-determined strategy listed on the survey. Table 3 provides a summary of respondents' ratings of use and relative effectiveness of pre-determined strategies from most frequent use to least frequent use. Although referral to Web- or print-based resources were used by $82 \%$ of respondents, the strategy was rated as moderately or very effective by only $61 \%$ of those using that strategy. In contrast, far fewer 
respondents (49\%) used intensive workplace disclosure counseling, with $96 \%$ of those respondents rating it as moderately or very effective.

Respondents were provided the option of rating "other" direct and indirect strategies. Other direct strategies were: (1) organizational policy regarding disclosure and accommodation; (2) counseling and therapy strategies like role-playing, intensive disclosure workshop and Dialectical Behavioural Therapy; (3) designated person in the workplace to support disclosure or non-disclosure decision-making; (4) education about workplace disclosure laws; (5) access to a peer mentor; (6) Greater Involvement of people living with HIV (GIPA) [29] in the workplace; (7) use of drama, music, dance, and poetry to educate those with language barriers; and (8) one-onone cultural support in own language. Other indirect strategies that were rated as moderately or very effective included: (1) organizational policy allowing for employment and accommodation without disclosure of a specific health condition; (2) legal advice and education regarding implications of disclosing or not disclosing; and (3) prompt referral to a support person appropriate for the individual situation.

Regarding indirect strategies to support people living with HIV who are making workplace disclosure decisions, respondents who indicated that they used internal referrals as a strategy were asked to describe the strategy. Most commonly, internal referrals were made to case management and/or peer support programs. Next most commonly, internal referrals were to health professionals, such as counselors, social workers, nurses, and therapists. A couple of respondents made internal referrals to human resources managers, a manager or supervisor, or an infectious disease coordinator. Respondents made external referrals most frequently to organizations that focus specifically on providing supports to people living with HIV, noting these organizations provide case management, access to peer support programs and counseling. The next most common external referrals were to health services (including mental health services), HIV-specific clinics, public health clinics, women's health programs, Indigenous health programs, occupational health nursing, outreach nursing, counselling, a local psychologist, and a help line. Referral to legal services was also common. One respondent noted referral to labour services, and another respondent noted not having anyone in the geographic area who deals with supporting HIV disclosure decisions. Some respondents stated that external referrals depended on each person's specific needs and the resources available in their communities.

\subsection{Values, barriers and supports}

The open-ended responses to our request for lists of values, barriers and supports that affect workplace disclosure decisions yielded 665 items. Rights, personal values and societal values are the three themes that characterize the values that respondents identified as affecting decision-making about workplace disclosure. Values expressed as rights most prominently included rights to privacy, to choose and to be treated fairly. Prominent personal values included respect, honesty, trust and self-determination. Other societal or institutional values, such as need to know, confidentiality, stigma, security and public safety were also considered to influence the decisions that people make about disclosure.

Felt and enacted stigma, lack of knowledge and support, and personal vulnerabilities are the four themes that characterize the barriers identified. Some participants noted that felt stigma could be a barrier to decision-making. Enacted, and fear of enacted, HIVrelated stigma included being discriminated against and treated differently by colleagues at work as well as fear of job loss, persecution, prosecution and third party disclosure. One respondent commented: "Even though HIV is now a chronic disease, the stigma is immense and unless we can overcome this there is really no meaning to the scientific advances which have been made."

Another commented:

"This is still a very difficult choice for an individual to make around disclosure especially in the food industry. If they are not internally discriminated against then the general public will discriminate (don't go to such and such restaurant...the cook has AIDS) that type of responses based on hatred and lack of knowledge."

Lack of knowledge related to rights and legislation, workplace policies, HIV and its transmission frequently were noted as barriers.

"There are still, at this time so many that know nothing truthful about HIV. All employers and their employees need education to help reduce fear and stigma around HIV and those living with this disease."

Individual vulnerabilities increased the perceived risks associated with a disclosure during the 
Table 4

Themes, sub-themes and descriptors of factors that support disclosure decisions derived from respondents' open-ended responses

\begin{tabular}{|c|c|c|}
\hline Personal supports & $\begin{array}{l}\text { Workplace } \\
\text { supports }\end{array}$ & Societal supports \\
\hline $\begin{array}{l}\text { Counselling } \\
\text { - Confidential and } \\
\text { non-judgemental } \\
\text { one-on-one support } \\
\text { (e.g., talking in through } \\
\text { before making a } \\
\text { decision) } \\
\text { - Support from an } \\
\text { agency } \\
\text { - Supports from } \\
\text { counsellors at work } \\
\text { - Professional support } \\
\text { to help with decision } \\
\text { making } \\
\text { Peer and Family } \\
\text { - Being connected } \\
\text { with a peer, } \\
\text { including peer } \\
\text { navigator } \\
\text { - Knowing others who } \\
\text { have disclosed their } \\
\text { status } \\
\text { Partner support } \\
\text { - Family support } \\
\text { Knowledge } \\
\text { - Gaining knowledge } \\
\text { about: } \\
\text { - HIV and how it affects } \\
\text { one's life } \\
\text { - Legal or ethical } \\
\text { obligations to disclose } \\
\text { - What disclosure means } \\
\text { to individuals and } \\
\text { coworkers } \\
\text { - Privacy rights related to } \\
\text { health } \\
\text { and }\end{array}$ & $\begin{array}{l}\text { Environment } \\
\text { - Workplace culture that is } \\
\text { well-informed, open, } \\
\text { friendly, safe, supportive, } \\
\text { respectful, compassionate, } \\
\text { inclusive, confidential and } \\
\text { accommodating } \\
\text { - Confidentiality and trust in } \\
\text { the employer } \\
\text { - Management and } \\
\text { supervisor support } \\
\text { - Relationship building } \\
\text { - Open policy around } \\
\text { speaking about health } \\
\text { concerns } \\
\text { Policies } \\
\text { - Policies that make clear the } \\
\text { confidentiality rights of } \\
\text { employees with regards to } \\
\text { the disclosure of any } \\
\text { medical condition } \\
\text { - Clear and enforced } \\
\text { operational workplace } \\
\text { policies with regards to } \\
\text { health related matters, } \\
\text { disclosure and } \\
\text { accommodation with the } \\
\text { right to appeal } \\
\text { - Anti-discrimination, } \\
\text { non-harassment and } \\
\text { respectful workplace } \\
\text { policies } \\
\text { - Support teams (including } \\
\text { health-related) }\end{array}$ & $\begin{array}{l}\text { Values/Attitudes } \\
\text { - GIPA/MEPA } \\
\text { frameworks } \\
\text { - Privacy, } \\
\text { confidentiality, and } \\
\text { respect for } \\
\text { disclosure choice } \\
\text { - Safe and supportive } \\
\text { environments } \\
\text { - Access to health } \\
\text { benefits for all (no } \\
\text { 'two tiered system' } \\
\text { for those with a } \\
\text { pre-existing } \\
\text { condition) } \\
\text { Accessible Resources } \\
\text { - ASO supports } \\
\text { - Legal support } \\
\text { - Protection of legal } \\
\text { rights } \\
\text { - Print resources } \\
\text { - Decision-making } \\
\text { tool listing pros and } \\
\text { cons of disclosure }\end{array}$ \\
\hline
\end{tabular}

decision-making process. Respondents identified several issues that could result in increased vulnerability to potential negative consequences of disclosure including stress, concern about personal safety, financial instability, inability to communicate in the dominant language, and immigration status. Peer pressure was also a concern for some.

Three themes categorize supports affecting decision-making into personal, workplace, or societal contexts. Table 4 provides themes, sub-themes and descriptors of supports that respondents identified. Notably, peer support, especially from others who have had disclosure experience, was prominent in responses especially from those who identified as living with HIV. Counselling from agencies, counsellors and families was also identified. Education and advocacy about HIV, disclosure and associated laws and rights, and many aspects of the workplace were considered supports affecting decision-making. Additionally, several specific strategies and actions were listed as supports affecting decision-making. These included decision-making assistance, discussion, role-playing, and community partnerships. One participant suggested that a good workplace support for disclosure involved a:

"Confidential decision-making process of disclosure in the environment where you are protected by agency policies and supported by the Executive Director, and whatever your decision you are accommodated no matter what choice you make."

In the additional comments section of the survey, some respondents noted that they felt disclosing HIV status in most workplace scenarios is unnecessary or 
not relevant. One respondent noted the importance of understanding the pros and cons of a decision.

"Maybe I'm getting paranoid when it comes to disclosure, but with the impressive amount of bad experiences I heard, I'm taking all the time I can to talk with people, make them evaluate the pros and cons at the same time, telling them that it is a very personal decision with big consequences."

In all responses related to the values, barriers and supports related to disclosure, self-determination and respect were clearly important as captured in the following comment of one respondent:

"Respect for an individual's process and their right to make the best decision for themselves and to have control over how their status is disclosed and how that information is used and/or shared."

\section{Discussion}

The complexity of disclosure decision-making manifests in many ways. The results of this study are consistent with other research and conceptualization of disclosure decision-making that people consider multiple personal and environmental factors [17]. In this study, respondents noted reluctance to consider disclosure in work environments where support for those living with HIV is unknown. Particularly for people living with HIV with intersecting forms of stigmatization, such as race, gender diversity or sexual orientation, disclosure in workplaces that lack knowledge and acceptance of HIV and other diversities, can be very challenging [30].

This study has demonstrated that, although many respondents were supporting people living with HIV in a number of ways, few had extensive experience supporting a person regarding whether or not to disclose their HIV status in the workplace. Respondents working in HIV-specific organizations were more confident in their abilities to support workplace disclosure decisions and in the resources available. This is not surprising considering the frequency and intensity with which these organizations address the diverse needs of people living with HIV. However, not everyone living with HIV uses the services of an HIV-specific organization; many receive treatment in hospitals and/or primary care settings that may have less capacity and expertise to support workplace disclosure decisions. Previous research has demonstrated that people who use ASOs tend to have higher needs than people who don't [31]. For example, a recent study from Ontario, Canada provided estimates that almost $75 \%$ of users of ASOs in that province experience some form of food insecurity [32]. ASOs are not geographically accessible to many people living in rural and remote areas. In addition, people who wish to conceal their HIV status may not want to obtain services from an HIV-specific organization. Our findings suggest that the supports available to assist people living with HIV to make workplace disclosure decisions are fewer for people not using the services of HIV-specific organizations, either by choice or by geographic inaccessibility. Providing decision-making support through other means, such as technologies that have a wider reach or provide more privacy [33], may help address this need.

Respondents provided important information about the strategies they used to assist people living with HIV to make workplace disclosure decisions. Many used diverse and multiple strategies. Interestingly, the strategy used by the most respondents was referral to Web- or print-based resources, but less than two-thirds of those who use the strategy considered it moderately or very effective. On the other hand, nearly all of the respondents who use intensive disclosure counseling believed it to be moderately or very effective. The resources needed for intensive disclosure counseling far outweigh those required for providing a print or online resource. For some people, a structured and interactive approach may be needed to help them weigh the implications of disclosure options and make decisions that are best for them. The findings from the open-ended responses reinforced the importance of peer-based support, a strategy for supporting people living with HIV that is highly favored in the literature [34-36]. In our study, respondents living with HIV had more experience and were more confident in supporting workplace decision-making than respondents who are not living with HIV. Assistance to seek out and navigate resources, and share perspectives and concerns with someone who has faced similar challenges can be emotionally helpful and empowering [37].

The results of this study highlighted the important role, not only of service providers, but also of workplaces and society in supporting disclosure decisions. The most commonly referenced open-ended response, when asked what values people hold that affect their decisions regarding workplace disclosure, was the right to privacy and confidentiality of health information at work. Knowing the high price that some people have had to pay for willingly disclosing 
chronic health issues in the workplace, a continuing and deeply stigmatized condition such as HIV was seen to carry with it a high-risk for disclosure [13,38]. Informed, self-determination of disclosure and the decision-making process was highly valued. Disclosure decisions in the context of the prevailing stigma of HIV can be a self-management strategy for people living with HIV as they anticipate how disclosure will influence their overall health and well-being $[17,39]$. To ease the burden of potential negative consequences of disclosure decisions, respondents reinforced the importance of a respectful workplace culture that is accepting of diversity and has clear and enforced policies that uphold employees' rights. Social policies and laws that protect rights, the Greater Involvement of People Living with HIV (GIPA) [29] and the Meaningful Engagement of People Living with HIV (MEPA) principles, and access to resources were also viewed as important to disclosure decision-making.

The primary contribution of this research is to add to what is known about the variability and complexity of providing supports for decision-making regarding disclosure of HIV status in workplaces. A complex constellation of supports is needed to address the issue of disclosure. Increased supports for people living with HIV that include education and counseling that can be accessed in different ways in diverse environments are required. Combining these elements into a decision support tool that provides information and opportunities for personal reflection on one's own values and workplace context may be a useful future direction. Providing resources and capacity-building for health and social care workers to support people with making and implementing disclosure decisions, as well as coping with the consequences the decisions will be useful [13]. In addition, there is a large role for educating and facilitating the development of supportive cultures in diverse workplaces. Workplaces need to enforce workplace policies that protect the rights, dignity and privacy of employees and facilitate environments that are open, ethical and respectful. Future research should continue to amass evidence for ways to support disclosure decisions and practical ways to create supportive environments.

\subsection{Limitations}

We described the current state of supports for workplace disclosure limiting analysis of causal pathways. Respondents were predominantly people who worked at HIV-specific organizations, so our results are biased toward this service sector. The sample size of 94 was limited in size. The survey was distributed electronically and, although we offered the option of obtaining a hard copy of the survey, no one requested one. Therefore, potential respondents without Internet access during the data collection period would not be able to respond. Due to the restricted nature of any survey and the use of Likert scale response options, respondents may have had other experiences and responses that they were not able to depict accurately in this format. We addressed this limitation by including open-ended questions that encouraged respondents to provide perspectives in their own words.

\section{Conclusions}

People living with HIV are living longer and healthier lives, and the potential for obtaining and maintaining long-term employment is a reality for many. Decisional conflict about whether, or not, to disclose one's HIV status can arise for diverse personal and contextual reasons. The results of this cross-sectional survey research identified a broad constellation of strategies available to assist people to make this highly personal decision. However, many service providers who responded to the survey lacked confidence to support people in workplace disclosure decision-making, suggesting the need for more capacity building for service providers and workplaces in this area. In addition, we identified the need for supports that are more widely available, particularly for people who do not use the services of HIV-specific organizations.

\section{Acknowledgments}

We are grateful to all the people who responded to this survey. Funding was received from a College of Rehabilitation Sciences University of Manitoba Catalyst Research Grant.

\section{Conflict of interest}

None to report.

\section{References}

[1] Deeks SG, Lewin SR, Havlir DV. The end of AIDS: HIV infection as a chronic disease. The Lancet. 2013;382(9903): 1525-33. 
[2] O'Brien KK, Bayoumi AM, Strike C, Young NL, Davis AM. Exploring disability from the perspective of adults living with HIV/AIDS: Development of a conceptual framework. Health Qual Life Outcomes. 2008;6:76.

[3] Nasi M, De Biasi S, Gibellini L, Bianchini E, Pecorini S, Bacca V, Guaraldi G, Mussini C, Pinti M, Cossarizza A. Ageing and inflammation in patients with HIV infection. Clinical and Experimental Immunology. 2017;187(1):4452. doi: 10.1111/cei.12814

[4] Bengtson AM, Chibwesha CJ, Westreich D, MubianaMbewe M, Chi BH, Miller WC, Mapani M, Pence BW, Musonda P, Stringer JSA, Pettifor A. A risk score to identify HIV-infected women most likely to become lost to followup in the postpartum period. AIDS Care. 2016;28(8):103545. doi: 10.1080/09540121.2016.1144869

[5] Worthington C, O'Brien K, Zack E, McKee E, Oliver B. Enhancing labour force participation for people living with HIV: A multi-perspective summary of the research evidence. AIDS Behav. 2012;16(1):231-43.

[6] Rueda S, Raboud J, Mustard C, Bayoumi A, Lavis JN, Rourke SB. Employment status is associated with both physical and mental health quality of life in people living with HIV. AIDS Care. 2011;23(4):435-43.

[7] Escovitz K, Donegan K. Providing effective employment supports for persons living with HIV: The KEEP project. Journal of Vocational Rehabilitation. 2005;22(2):105-14.

[8] Nachega JB, Uthman OA, Peltzer K, Richardson LA, Mills EJ, Amekudzi K, Ouédraogof A. Association between antiretroviral therapy adherence and employment status: Systematic review and meta-analysis. Bull World Health Organ. 2015;93(1):29-41. doi: http://dx.doi.org/10.2471/ BLT.14.138149

[9] O'Brien KK, Ibanez-Carrasco F, Solomon P, Harding R, Cattaneo J, Chegwidden W, Gahagan J, Baxter L, Worthington C, Gayle P, Merritt B, Baltzer-Turje R, Iku N, Zack E. Advancing research and practice in HIV and rehabilitation: A framework of research priorities in HIV, disability and rehabilitation. BMC Infect Dis. 2014;14:724. doi: 10.1186/s12879-014-0724-8

[10] Restall GJ, Carnochan TN, Roger KS, Sullivan TM, Etcheverry EJ, Roddy P. Collaborative priority setting for human immunodeficiency virus rehabilitation research: A case report. Canadian Journal of Occupational Therapy. 2016;83(1):7-13.

[11] Fesko SL. Disclosure of HIV status in the workplace: Considerations and strategies. Health and Social Work. 2001;26(4):235-44.

[12] Henry E, Bernier A, Lazar F, Matamba G, Loukid M, Bonifaz C, Diop S, Otis J, Preáu M, The Partages study group. "Was it a mistake to tell others that you are infected with HIV?": Factors associated with regret following HIV disclosure among people living with HIV in five countries (Mali, Morocco, Democratic Republic of the Congo, Ecuador and Romania). Results from a community-based research. AIDS and Behavior. 2015;19(2):311-21. doi: 10.1007/s10461014-0976-8

[13] Obermeyer CM, Baijal P, Pegurri E. Facilitating HIV disclosure across diverse settings: A review. American Journal of Public Health. 2011;101(6):1011-23.

[14] Poindexter CC, Shippy RA. HIV diagnosis disclosure: Stigma management and stigma resistance. Journal of Gerontological Social Work. 2010;53(4):366-81.

[15] Stutterheim SE, Brands R, Baas I, Lechner L, Kok G, Bos AER. HIV status disclosure in the workplace: Positive and stigmatizing experiences of health care workers living with
HIV. J Assoc Nurses AIDS Care. 2017;28 923-937. doi: 10.1016/j.jana.2017.06.014

[16] Mak WWS, Mo PKH, Ma GYK, Lam MYY. Metaanalysis and systematic review of studies on the effectiveness of HIV stigma reduction programs. Social Science \& Medicine. 2017;188(Supplement C):30-40. Doi: 10.1016/j.socscimed.2017.06.045

[17] de Vries DH, Koppen L, Lopez AM, Foppen R. The vicious cycle of stigma and disclosure in "self-management": A study among the Dutch HIV population. AIDS Education and Prevention. 2016;28(6):485-98.

[18] Rouleau G, Côté J, Cara C. Disclosure experience in a convenience sample of Quebec-born women living with HIV: A phenomenological study. BMC Women's Health. 2012;12. http://www.biomedcentral.com/1472-6874/12/37

[19] Chaudoir SR, Fisher JD, Simoni JM. Understanding HIV disclosure: A review and application of the Disclosure Processes Model. Social Science and Medicine. 2011;72(10):1618-29.

[20] Brooks RA, Klosinski LE. Assisting persons living with HIV/AIDS to return to work: Programmatic steps for AIDS service organizations. AIDS Education and Prevention. 1999;11(3):212-23.

[21] Ferrier SE, Lavis JN. With health comes work? People living with HIV/AIDS consider returning to work. AIDS Care. 2003;15(3):423-35.

[22] Torres-Madriz G, Lerner D, Ruthazer R, Rogers WH, Wilson IB. Work-related barriers and facilitators to antiretroviral therapy adherence in persons living with HIV infection. AIDS Behav. 2011;15(7):1475-82.

[23] Palar K, Martin A, Oropeza Camacho ML, Derose KP. Livelihood experiences and adherence to HIV antiretroviral therapy among participants in a food assistance pilot in Bolivia: A qualitative study. PLos One. 2013;8(4):e61935.

[24] Degroote S, Vogelaers D, Koeck R, Borms R, De Meulemeester L, Vandijck D. HIV disclosure in the workplace. Acta Clinica Belgica. 2014;69(3):191-3.

[25] Wagener MN, Van Opstal SEM, Miedema HS, Van Gorp ECM, Roelofs PDDM. Work-related stigma and disclosure: A daily challenge for people living with HIV A scoping review of the literature. Work. 2017;58(4):537-48.

[26] Dillman DA, Smyth JD, Christian LM. Internet, phone, mail, and mixed-mode surveys: The tailored design method. 4th ed. Hoboken, New Jersey: Wiley; 2014.

[27] Harris PA, Taylor R, Thielke R, Payne J, Gonzalez N, Conde JG. Research Electronic Data Capture (REDCap) A metadata-driven methodology and workflow process for providing translational research informatics support. Journal of Biomedical Informatics. 2009;42(2):377-81.

[28] Thomas DR. A general inductive approach for analyzing qualitative evaluation data. American Journal of Evaluation. 2006;27(2):237-46.

[29] UNAIDS. The greater involvement of people living with HIV (GIPA). 2007 [Available from: http://data.unaids. org/pub/briefingnote/2007/jc1299_policy_brief_gipa.pdf.

[30] Wagener MN, Roelofs P, Miedema HS, Brandjes DP, Dahmen R, van Gorp, ECM. The development of a multidisciplinary, evidence-based guideline for "HIV and employment". AIDS Care. 2015;27(2):133-41. http://dx.doi. org/10.1080/09540121.2014.952612

[31] Williams P, Narciso L, Browne G, Roberts J, Weir R, Gafni A. Characteristics of people living with HIV who use community-based services in Ontario, Canada: Implications for service providers. Journal of the Association of Nurses in AIDS Care. 2005;16(4):50-63. 
[32] Bekele T, Globerman J, Watson J, Jose-Boebridge M, Kennedy R, Hambly K, Anema A, Hogg RS, Rourke SB, Canada CIHR Food Security Study Team. Prevalence and predictors of food insecurity among people living with HIV affiliated with AIDS service organizations in Ontario, Canada. AIDS Care. 2018;30:5, 663-671. doi: 10.1080/095 40121.2017.1394435

[33] Giliauskas D, Mitra S, Globerman J, Bacon J. Northern exposures backgrounder: Searching for best practices in rural and remote care. Ontario HIV Treatment Network; 2015. Retrieved from: http://www.ohtn.on.ca/northern-exp osures/wp-content/uploads/sites/8/2016/01/Northern-Back grounder.pdf

[34] Huff A, Chumbler N, Cherry CO, Hill M, Veguilla V. An indepth mixed-methods approach to Ryan White HIV/AIDS care program comprehensive needs assessment from the Northeast Georgia Public Health District: The significance of patient privacy, psychological health, and social stigma to care. Eval Program Plann. 2015;49:137-48.

[35] Simoni JM, Nelson KM, Franks JC, Yard SS, Lehavot K. Are peer interventions for HIV efficacious? A systematic review. AIDS Behav. 2011;15(8):1589-95.
[36] O'Brien N, Greene S, Carter A, Lewis J, Nicholson V, Kwaramba G, Menard B, Kaufman E, Ennabil N, Andersson N, Loutfy M, de Pokomandy A, Kaida A, CHIWOS Research Team. Envisioning women-centered HIV Care: Perspectives from women living with HIV in Canada. Women's Health Issues. 2017;27(6):721-30.

[37] Peterson JL, Rintamaki LS, Brashers DE, Goldsmith DJ, Neidig JL. The forms and functions of peer social support for people living with HIV. Journal of the Association of Nurses in AIDS Care. 2012;23(4):294-305.

[38] Elopre L, Hook EW, Westfall AO, Zinski A, Mugavero MJ, Turan J, Wagoner, NV. The role of early HIV status disclosure in retention in HIV care. AIDS Patient Care and STDs. 2015;29(12):646-50. doi: 10.1089/apc.2015.0205

[39] McDonald K, Slavin S, Pitts MK, Elliott JH. Chronic disease self-management by people with HIV. Qualitative Health Research. 2015;26(6):863-70. 